\title{
Interactive effects of herbivory and substrate orientation on algal community dynamics on a coral reef
}

\author{
Alain Duran $^{1}$ (D) L. Collado-Vides ${ }^{1,2} \cdot$ L. Palma ${ }^{1} \cdot$ D. E. Burkepile ${ }^{3,4}$
}

Received: 14 March 2018 / Accepted: 1 September 2018

(c) The Author(s) 2018

\begin{abstract}
Herbivory is a significant driver of algal community dynamics on coral reefs. However, abiotic factors such as the complexity and orientation of the benthos often mediate the impact of herbivores on benthic communities. We experimentally evaluated the independent and interactive effects of substrate orientation and herbivorous fishes on algal community dynamics on a coral reef in the Florida Keys, USA. We created horizontal and vertical substrates, mimicking the trend in the reduction of vertical surfaces of coral reefs, to assess how algal communities developed either with herbivory (open areas) or without herbivory (herbivore exclosures). We found that substrate orientation was the dominant influence on macroalgal community composition. Herbivores had little impact on community development of vertical substrates as crustose algae dominated these substrates regardless of being in exclosures or open areas. In contrast, herbivores strongly impacted communities on horizontal substrates, with upright macroalgae (e.g., Dictyota spp., articulated coralline algae) dominating herbivore exclosures, while filamentous turf algae and sediment dominated open areas. Outside of exclosures, differences between vertical and horizontal substrates exposed to herbivores persisted despite similar intensity of herbivory. Our results suggest that the orientation of the reef benthos has an important impact on benthic communities. On vertical surfaces, abiotic factors may be more important for structuring algal communities while herbivory may be more important for controlling algal dynamics in flatter areas. Thus, the decline in structural complexity of Caribbean coral reefs and the flattening of reef substrates may fundamentally alter the impact that herbivores have on benthic community dynamics.
\end{abstract}

\section{Introduction}

Responsible Editor: P. Kraufvelin.

Reviewed by V. Jormalainen and an undisclosed expert.

Electronic supplementary material The online version of this article (https://doi.org/10.1007/s00227-018-3411-2) contains supplementary material, which is available to authorized users.

Alain Duran

adura023@fiu.edu

1 Department of Biological Sciences, Florida International University, 11200 S.W. 8th St., Miami, FL 33199, USA

2 Center for Coastal Oceans Research in the Institute for Water and Environment, 11200 S. W. 8th St., Miami, FL 33199, USA

3 Department of Ecology, Evolution and Marine Biology, University of California, Santa Barbara, Santa Barbara, CA 93106, USA

4 Marine Science Institute, University of California, Santa Barbara, Santa Barbara, CA 93106, USA
Herbivory is a fundamental process on coral reefs that regulates algal species composition, algal abundance (Ogden and Lobel 1978; Lewis and Wainwright 1985; Carpenter 1986) and the interactions between corals and algae (Mapstone et al. 2007; Trapon et al. 2013a, b; Zaneveld et al. 2016). On Caribbean coral reefs, sea urchins like the long-spined sea urchin (Diadema antillarum) and herbivorous fishes [Family Acanthuridae (surgeonfishes) and Family Labridae, tribe Scarini (parrotfishes)] are often the most abundant herbivores (Steneck 1983; Adam et al. 2015a). A die-off of sea urchins in the 1980s left fishes as the main herbivores on Caribbean reefs (Lessios 1988), although they are currently overfished in many areas (Jackson et al. 2014). Reduced herbivory and concurrent declines in coral cover have facilitated increases in macroalgal cover, which has doubled Caribbean-wide since the 1970s (Jackson et al. 2014). Declines in coral abundance coupled with increased bioerosion rates have resulted in an overall negative carbon budget on many reefs, driving reductions of structural complexity on many 
reefs throughout the region (Alvares-Filip et al. 2011; Perry et al. 2014).

The structural complexity of coral reefs largely comprised the three-dimensional physical structure built by scleractinian corals and other calcifying organisms that provide shelter, settlement opportunities, and foraging habitat to reef-dwelling organisms (Wilson et al. 2007; Graham and Nash 2013). Areas with higher structural complexity often have more abundant sea urchins (Fabricius et al. 2014) and herbivorous fishes (Luckhurst and Luckhurst 1978; Graham 2014; Rogers et al. 2014), which may increase topdown control on algal communities (Verges et al. 2011). For instance, crustose coralline algae (CCA), which commonly dominate areas with high herbivory (Steneck 1997), are often more abundant on reefs with higher complexity and more steeply sloped substrates (Fabricius and De'ath 2001). However, in the Caribbean, the structural complexity of coral reefs has declined by more than $50 \%$ since the 1960 s, creating flatter, more horizontal reef surfaces (Alvares-Filip et al. 2009, 2011). Thus, there is a critical need to understand how the loss of structural complexity and the flattening of coral reefs influence herbivory and algal community dynamics.

Reduced structural complexity on reefs could alter herbivory, and consequently algal dynamics, through several mechanisms (Bozec et al. 2013, 2015). For instance, lower complexity reefs provide less shelter for herbivorous fishes, which may reduce herbivory and result in more macroalgae (Verges et al. 2011). Additionally, more complex reefs may require more grazing pressure as a consequence of having more area that needs to be grazed by herbivores (Bozec et al. 2013). At a smaller scale, microtopographic complexity often influences grazing dynamics by giving differential access to different species of herbivorous fishes, which alters the diversity of algae and abundance of juvenile corals on the scale of centimeters (Brock 1979; Brandl and Bellwood 2016). Furthermore, the flattening of reef substrates could increase sediment accumulation, which, in turn, can reduce grazing activity and promote the growth of filamentous algae (Goatley and Bellwood 2013; Clausing et al. 2014). Conversely, benthic areas with steeper slopes tend to have less sediment, which may facilitate herbivory and the abundance of CCA, including species [e.g., Titanoderma prototypum (Foslie) Woelkerling, Y.M. Chamberlain and P.C. Silva] that can facilitate coral recruitment (Arnold and Steneck 2010; Ritson-Williams et al. 2016). Therefore, the ongoing flattening of Caribbean coral reefs may have a strong impact on herbivores and their role as drivers of algal dynamics.

Here, we investigated how structural complexity can mediate the influence of herbivory on algal community dynamics on a reef in the Florida Keys, USA. We manipulated the orientation (horizontal vs. vertical) of experimental substrates using quarried coral limestone tiles to simulate bare substrate created after a disturbance. To examine the interaction between substrate orientation and herbivory, we established these substrates in areas with low (herbivore exclosures) or high (open areas) herbivory. We expected that substrate orientation would determine whether herbivores strongly impact the dynamics of benthic macroalgae. We predicted that herbivory would strongly impact algal communities on horizontal substrates with filamentous turf algae dominating in open areas and upright macroalgae dominating in exclosures as herbivores tend to retard algal succession (Diaz-Pulido and McCook 2002; Duran et al. 2016). On vertical substrates, we expected that herbivory would be less important, possibly as a consequence of reduced light (Roff et al. 2015), such that crustose algae would dominate vertical surfaces in open areas and in herbivore exclosures.

\section{Materials and methods}

\section{Study site}

We conducted our experiment from August 2013 to August 2014 on a low relief spur and groove reef near Conch Reef $\left(24^{\circ} 57.695^{\prime} \mathrm{W}, 80^{\circ} 27.230^{\prime} \mathrm{N}\right)$ in $\sim 7 \mathrm{~m}$ of water located in the upper Florida Keys, USA. These reefs are regularly dominated by turf algae with seasonal peaks of Stypopodium zonale in the spring months and Dictyota spp. in the summer months (Zaneveld et al. 2016). Reefs in the Florida Keys have very low sea urchin density $\left(<0.1\right.$ Ind. $\mathrm{m}^{-2}$; Chiappone et al. 2008) and high abundance of herbivorous fishes (Burkepile et al. 2013) including large parrotfishes currently considered rare Caribbean-wide (Adam et al. 2015b).

\section{Experimental manipulation}

We used quarried coral limestone tiles $(2.5 \times 10 \times 10 \mathrm{~cm})$ to create bare vertical and horizontal substrates that mimic areas of reef with distinct substrate orientation (Fig. 1). We assembled four tiles next to each other to construct flat squares $\left(20 \times 20 \mathrm{~cm} ; 400 \mathrm{~cm}^{2}\right.$ total area) of horizontal substrate and four tiles stacked to create vertical substrates $\left(10 \times 10 \mathrm{~cm}\right.$ per side for $400 \mathrm{~cm}^{2}$ total area by adding all four sides; Fig. 1b). We did not include the horizontal surface on the top of the vertical tiles in any of the data collection to keep the area of the treatments the same. Because of the nature of this setup, the horizontal substrates had $40 \mathrm{~cm}$ of cracks, spaces where tiles met each other, while the vertical tiles had $120 \mathrm{~cm}$ of cracks. Thus, we only collected data on the exposed tile surfaces, not on the organisms growing within the cracks, to prevent this difference from confounding our quantification of the benthic communities.

In order to test the impact of herbivory on algal communities, we placed two sets of each substrate type inside 
Fig. 1 Experimental design showing the dimensions of substrates in open areas (left) and herbivore exclosures (right). Notice that each vertical substrate encompasses four $(10 \times 10 \mathrm{~cm})$ vertical walls that are the same area as horizontal substrates $\left(20 \times 20 \mathrm{~cm}=400 \mathrm{~cm}^{2}\right)$. Numbers indicate the dimensions in $\mathrm{cm} . n=3$ for each open area and herbivore exclosure

\section{Experimental design}

Open area

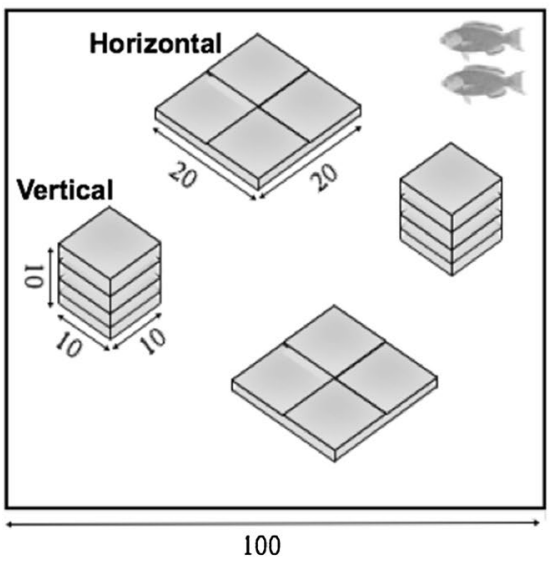

Herbivore exclosure plot

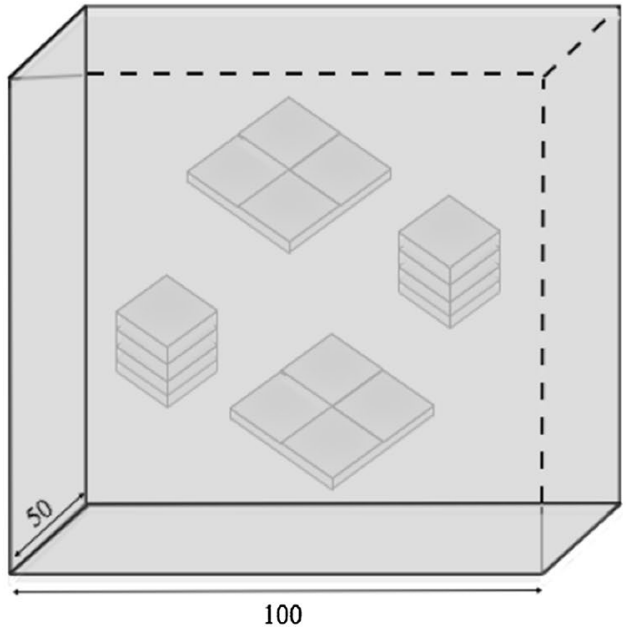

an exclosure plot $(1 \times 1 \times 0.5 \mathrm{~m})$. Exclosures were framed with stainless steel round bar and covered with PVCcoated wire mesh with $2.5 \mathrm{~cm}$ diameter holes to exclude herbivorous fishes ( 2 horizontal substrates and 2 vertical substrates within one exclosure). Another two sets of each substrate orientation were placed in each open area with open access to herbivorous fishes. Thus, the substrate orientation treatment was nested within either exclosures or open areas, creating four treatments: (1) horizontal substrates in open areas, (2) vertical substrates in open areas, (3) horizontal substrates in exclosures, and (4) vertical substrates in exclosures. Each of these treatments was replicated three times ( $n=3$ exclosures and $n=3$ open areas). All substrates were deployed in August 2013 and data collection began in September 2013 and continued until August 2014.

We did not include exclosure controls in our experiment as previous research suggested minimal effects of exclosure artifacts on algal communities in these shallow reef systems (Miller et al. 1999; Smith et al. 2001; Burkepile and Hay 2007). In fact, our recent study on a nearby reef showed no effects of exclosures on water flow, sedimentation, or algal communities using similarly designed exclosures (Zaneveld et al. 2016; see supplementary material therein for a discussion of potential exclosure artifacts). However, these exclosures do decrease light availability to the benthos by $\sim 15 \%$ (Ferrari et al. 2012). Given that the light availability common at these shallow depths saturates the photosystems of most primary producers (Carpenter 1985), the slight decrease in light availability likely had minimal impact on primary production or interactions among benthic organisms.

\section{Herbivorous fish feeding}

We recorded the grazing activity of parrotfishes and surgeonfishes on vertical and horizontal substrates in open areas using GoPro video cameras. Grazing activity was evaluated six times during the experiment: in September 2013, October 2013, December 2013, February 2014, April 2014, and May 2014. Cameras were placed $50 \mathrm{~cm}$ away from each plot between 1000 and 1400 hours to film grazing activity on both horizontal and vertical substrates simultaneously. To quantify grazing intensity on each substrate we selected 20 random 5-min periods from the 3 to $4 \mathrm{~h}$ of video during each deployment. We identified every fish that fed on the substrates to species and recorded life history stage (juvenile, intermediate, adult), as well as the type of substrate bitten (horizontal vs. vertical), and the number of bites during each feeding event. We did not include bites on the top of the vertical substrates (the flat horizontal portion on the top of the stack of tiles) to ensure we quantified bites in the same area on both vertical and horizontal substrates.

\section{Algal community dynamics}

Every 30-45 days between August 2013 and August 2014 ( $n=8$ sampling periods) we visually surveyed the benthic community on the vertical and horizontal substrates. To do so, we placed a $10 \times 10 \mathrm{~cm}$ grid divided into four quadrants over the substrate and visually estimated the percent of the substrate covered by different algal taxa to the nearest $5 \%$. We identified algae to the lowest taxonomic level possible and also grouped them into form-functional groups (FFG) following a modification of Steneck and Dethier (1994). We 
considered turf algae (hereafter "turf") as all short $(<1 \mathrm{~cm})$ filamentous algal species with little to no sediment trapped in the filaments (Connell et al. 2014). When these filamentous algal communities became longer ( $>2 \mathrm{~cm}$ height), they often trapped sediment within the filaments. Therefore, we classified this matrix as turf algae, following Connell et al. (2014) for the definition of turf, associated with sediment (henceforth "TAS" or 'turf and associated sediment'). When sediment was on the substrate but not associated with turf algae, it was classified as sediment.

\section{Statistical analysis}

We evaluated the effect of substrate orientation and month on herbivore grazing rates via Friedman tests. Unfortunately, no transformations were able to make the grazing rate data normal, and we had to resort to nonparametric statistics. We transformed the benthic percent cover data via Box-Cox transformations to meet assumptions of homoscedasticity and normality (as checked for using the Levene's test). After transformation, we used a linear mixed model (LMM) to test the effects of herbivory and substrate orientation over time (month) for each benthic group with plot as a random factor. We assessed changes in community composition through time for each treatment using non-metric multidimensional scaling (NMDS) analyses and permutational multivariate analysis of variance (PERMANOVA) with the distance matrix calculated using Bray-Curtis dissimilarity. We performed descriptive and inferential analyses using packages vegan (Oksanen et al. 2017), doBy (Soren 2016), MASS (Venables and Ripley 2002), ggplot2 (Wickham 2009) in the
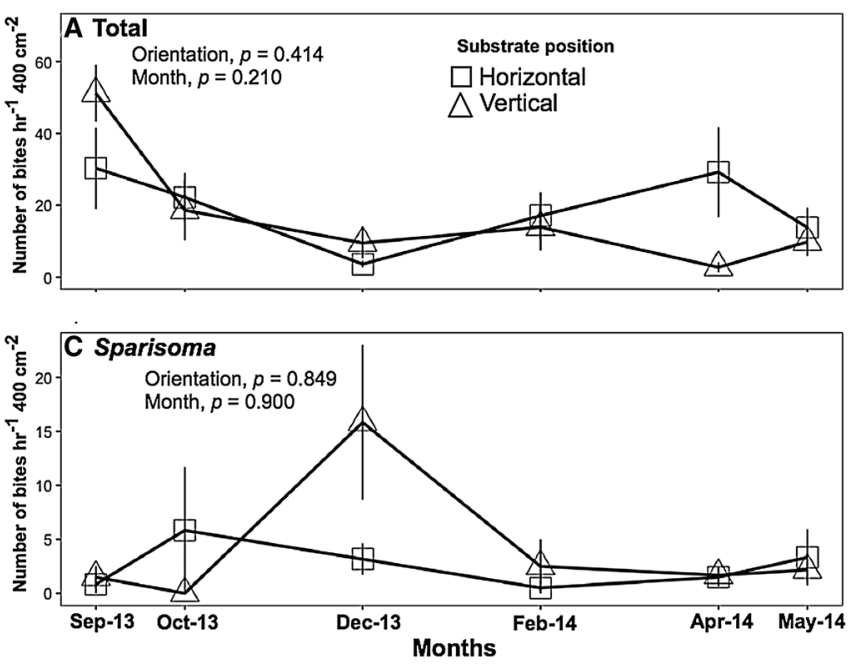

Fig. 2 Grazing rates by herbivorous fishes obtained from videos recorded in open areas. Points represent the number of bites taken by a all species of herbivorous fishes, b Acanthurus spp., c Sparisoma
R program created by R Development Core Team (2016), version, 3.2.2.

\section{Results}

\section{Herbivorous fish feeding}

Overall grazing rates of herbivores did not differ across time or between substrate orientation (horizontal or vertical) (Fig. 2a). Grazing rates by surgeonfishes were similar on both substrate orientations with an average of $7.4 \pm 2.0$ bites $\mathrm{h}^{-1} 400 \mathrm{~cm}^{-2}$ on horizontal substrates and $4.5 \pm 1.5$ bites $^{-1}$ $400 \mathrm{~cm}^{-2}$ on vertical substrates (Fig. 2b). While Sparisoma spp. and Scarus spp. parrotfishes took approximately 2 and 10 bites $\mathrm{h}^{-1} 400 \mathrm{~cm}^{-2}$, respectively, neither genus exhibited preferences for a specific substrate orientation (Fig. 2c, d).

\section{Algal community dynamics}

Substrate orientation was a strong determinant of algal community composition with horizontal and vertical substrates often differing regardless of herbivory (Figs. 3, 4). On vertical substrates, crustose algae covered more than $50 \%$ of the substrate after 6 months and remained the dominant benthic group regardless of herbivory treatment (Fig. 4a, see Appendix I in ESM for complete model results). Turf algae were often the second most abundant algal group on vertical substrates ranging from $3.4 \pm 0.6$ to $7.3 \pm 1.8 \%$ in exclosures and open treatments, respectively, with marginal differences between orientations (Fig. 4b, LMM, Orientation, $F_{1,62}=3.7, p=0.059$ ). Upright macroalgae (Dictyota
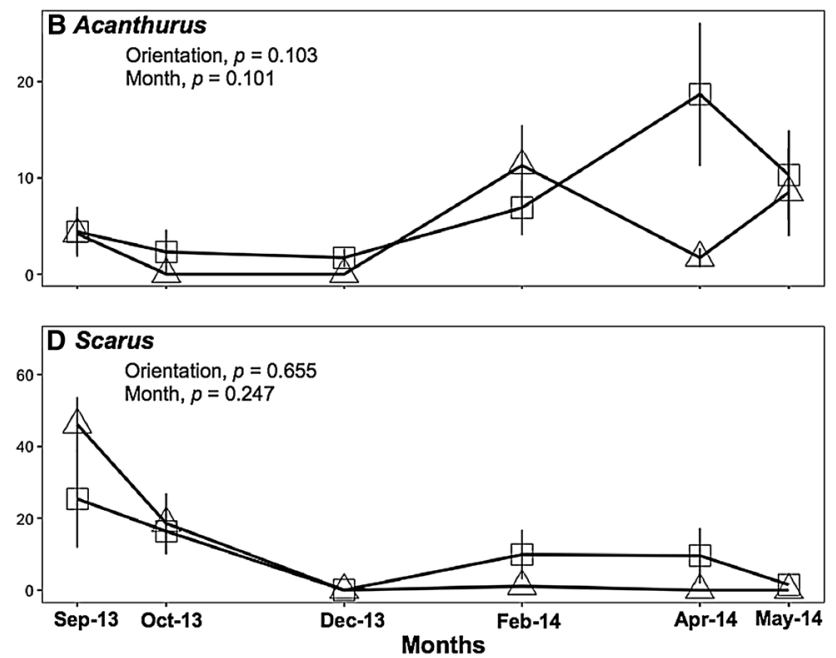

spp., or $\mathbf{d}$ Scarus spp. Data are mean \pm SE. Note that $Y$ axes vary in scale. Statistics are from Friedman tests 


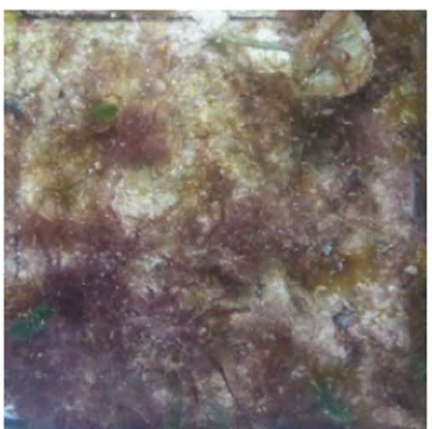

A Exclosure-Horizontal

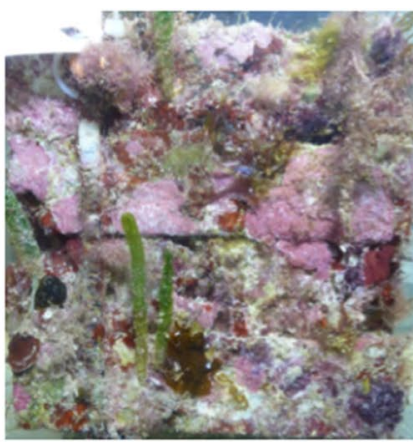

B Exclosure-Vertical

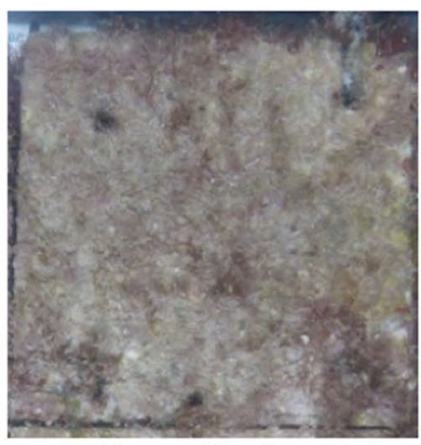

C Open-Horizontal

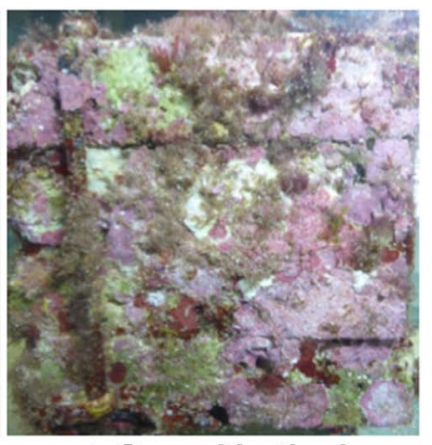

D Open-Vertical

Fig. 3 Photographs of community composition on experimental substrates at the end of the year-long experiment: a exclosure-horizontal, b exclosure-vertical, c open-horizontal, and d open-vertical substrates. Photos were taken on $10 \times 10 \mathrm{~cm}$ section of the substrates
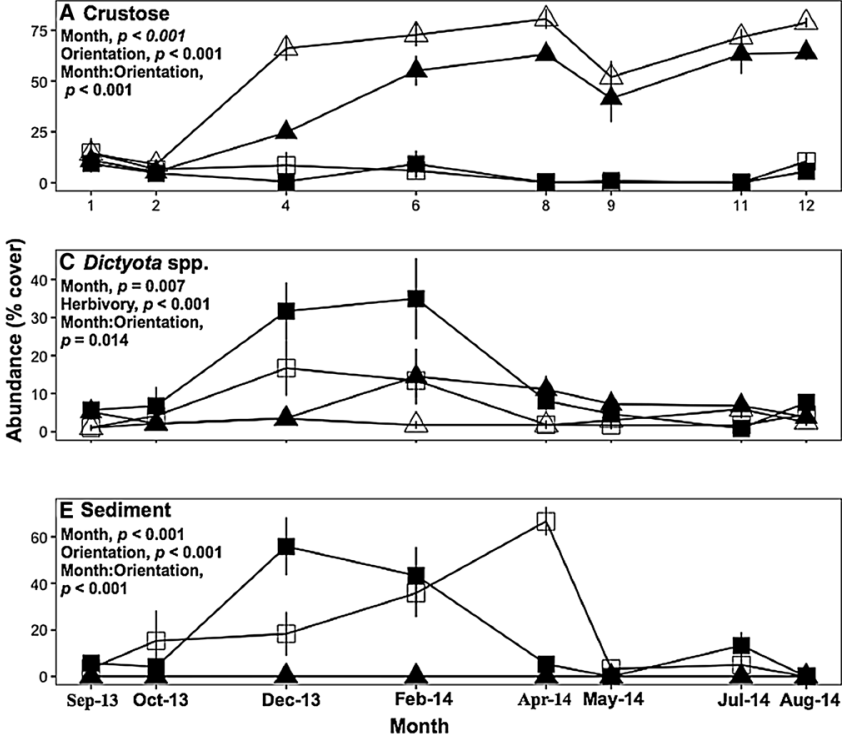

Fig. 4 Abundance of different benthic groups through time in different treatments: horizontal substrates in herbivore exclosures (exclosure-horizontal), vertical substrates in herbivore exclosures (exclosure-vertical), horizontal substrates in open areas (open-horizontal) and vertical substrates in open areas (open-vertical). a Crustose algae,

spp. and articulated calcareous algae), sediment, and TAS were rarely present on vertical substrates throughout the entire study regardless of herbivory (Fig. $4 \mathrm{c}-\mathrm{f}$ ).

Herbivory more strongly impacted algal communities on the horizontal substrates. On horizontal substrates in open areas, turf abundance remained below $25 \%$ for the first 9 months after which turf cover sharply increased to more than $50 \%$ (Fig. 4b, LMM, Month:Herbivory, $F_{7,62}=2.7$, $p=0.016$, see Appendix I in ESM for complete model results). Macroalgal abundance on horizontal substrates varied through time depending on the presence of herbivory. Dictyota dominated horizontal substrates in exclosures during early succession with a peak of $\sim 35 \%$ in February
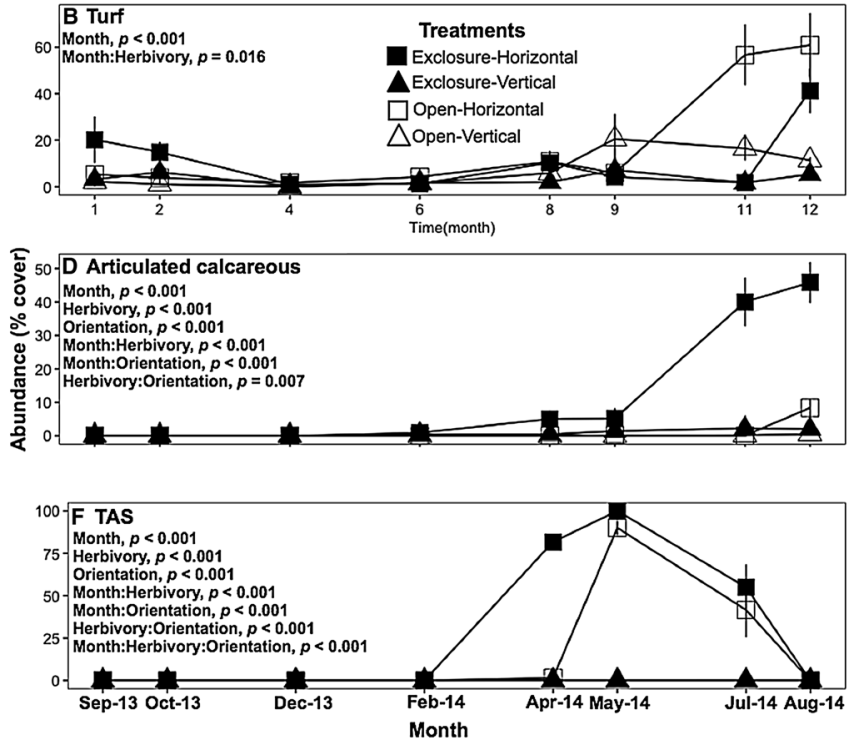

b turf algae, c Dictyota spp., d articulated calcareous algae, e sediment and $\mathbf{f}$ turf associated with sediment (TAS). Data are mean \pm SE. Note that $Y$ axes vary in scale. Statistics show significant effects from linear mixed models. See supplementary material for full model outputs

2014 followed by a drop of abundance to less than $10 \%$ (Fig. 4c, LMM, month:orientation, $F_{7,62}=4.8, p<0.001$ ). Turf associated with sediment (TAS) developed on horizontal substrates after a previous accumulation of sediment on the substrates (Fig. 4e, f). By May 2014, TAS was the most abundant group on horizontal substrates covering close to $100 \%$ of the substrate (Fig. 4f, LMM, orientation, $F_{1,62}=414.1, p<0.001$; month, $\left.F_{7,62}=106.8, p<0.001\right)$. However, after the peak in TAS on horizontal substrates, articulated calcareous algae (e.g., Amphiroa spp. and Jania spp.) became the dominant macroalgal group on horizontal substrates in herbivore exclosures, covering over $45 \%$ of the substrate by the end of the experiment (Fig. 4d, LMM, 
month, herbivory:orientation, $\left.F_{1,62}=7.9, p=0.007\right)$. Articulated calcareous algae were rare on horizontal tiles exposed to herbivores.

When we assessed the overall composition of macroalgal communities, both substrate orientation and herbivory led to differences in community composition over time (Fig. 5, see Appendix I in ESM for complete model results). However, substrate orientation explained the highest proportion of change in algal community (PERMANOVA, $R^{2}=0.19$ ) compared to herbivory (PERMANOVA, $R^{2}=0.02$ ) and showed a significant interaction with time (PERMANOVA, month:orientation, $\left.F_{1,191}=12.31, p=0.010\right)$. The NMDS suggested that the algal communities on vertical substrates followed similar temporal patterns regardless of herbivory. However, on horizontal substrates, herbivory appeared to drive a divergence of algal communities over time.

\section{Discussion}

The extent to which the loss of structural complexity on coral reefs mediates the influence of herbivory on benthic communities is an important, yet minimally addressed topic. Here, we show that substrate orientation is a key driver of algal community dynamics. We found that vertical substrates were primarily dominated by crustose algae with little upright macroalgae, regardless of the presence of herbivorous fishes. In contrast, upright macroalgae such as Dictyota spp. and articulated calcareous algae dominated horizontal

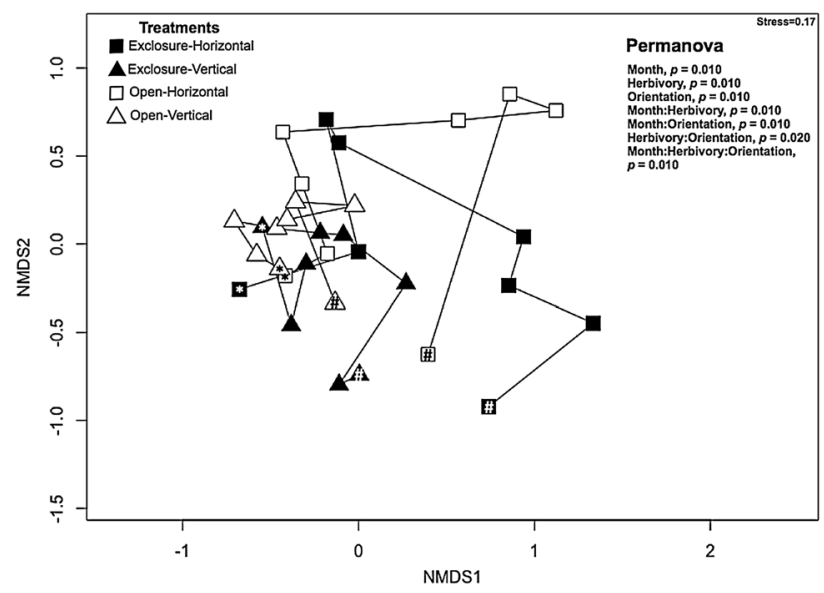

Fig. 5 Trajectory of macroalgal community composition using nonmetric multidimensional scaling (NMDS). The treatments represent: horizontal substrates in herbivore exclosures (exclosure-horizontal), vertical substrates in herbivore exclosures (exclosure-vertical), horizontal substrates in open areas (open-horizontal) and vertical substrates in open areas (open-vertical). Asterisk (*) represents the first time point after the benthic community developed (month 1) and pound symbol (\#) indicates the final time point. Statistics show significant effects from PERMANOVA. See supplementary material for full model outputs substrates when herbivorous fishes were absent. However, even in the presence of herbivores, filamentous turf algae and sediments dominated horizontal substrates in contrast to the crustose algae that dominated vertical substrates. These distinct differences in algal communities on vertical and horizontal substrates persisted despite similar intensity of herbivory on both orientations.

Several different abiotic and biotic factors may influence the impact of substrate orientation on macroalgal community composition. Vertical substrates are less likely to accumulate sediment, which can slow growth rates of CCA and reduce their abundance (Steneck 1997; Fabricius and De'ath 2001). Therefore, the lack of sediment on vertical tiles likely facilitated crustose algae, which was in stark contrast to high sediment loads (up to $60 \%$ cover during some periods) and low CCA cover on horizontal substrates. High sediment cover on horizontal substrates likely enhanced the retention and growth of new algal propagules (Steneck 1997) and facilitated the formation of a matrix of turf and associated sediment (TAS). Indeed, we observed that after 8 months of sediment accumulation on horizontal substrates, there was an increase of TAS to more than $75 \%$ cover, followed by an increased abundance of turf in open areas. The dominance of turf algae on horizontal substrates in open areas may be a function of accumulated sediment protecting turf forming algae from consumption by herbivorous fishes (e.g., Goatley and Bellwood 2013; Clausing et al. 2014; Gordon et al. 2016; Tebbett et al. 2017), although we did not see any obvious suppression of herbivory as sediment accumulated.

In contrast, reductions in herbivory strongly impacted the dynamics of algae on horizontal substrates within exclosure treatments. Herbivory often controls algal succession, with macroalgae increasing rapidly when herbivores are absent (Smith et al. 2010; Duran et al. 2016; Zaneveld et al. 2016). Our results corroborate previous findings, as horizontal substrates exposed to herbivores consistently had low cover of macroalgae and high cover of filamentous turf algae that are adapted to environments with intense grazing from herbivores (Carpenter 1986). Yet, in herbivore exclosures, macroalgae, particularly articulated calcareous algae that are typically rare where herbivory is high (e.g., Zaneveld et al. 2016), replaced turf algae over time. In contrast, herbivory had no effect on algal communities growing on vertical substrates as crustose algae dominated these substrates regardless of exclosure status. Crustose algae, potentially facilitated by their ability to proliferate under lower light conditions on the vertical substrates, are often well defended against herbivores by their crustose thallus (Steneck and Dethier 1994). In fact, herbivores often facilitate crustose algae by removing upright algae that would otherwise outcompete crustose taxa (Smith et al. 2010). Combined, our results suggest that the slope of reef habitats can strongly influence benthic community composition and regulate the 
importance of herbivory for structuring algal communities, at least at small spatial scales.

Although we did not measure light levels in our experiment, light exposure on vertical tiles was likely significantly lower compared to horizontal substrates as similar experiments have shown (Strader et al. 2015). These differences in light intensity could have influenced the differences in algal composition found between the two substrates. Lower light levels can facilitate certain CCA species (e.g., Titanoderma sp.) in crevices on shallow reefs or exposed areas on deeper reefs (Steneck and Dethier 1994). Although some CCA species (e.g., Porolithon sp. and Lithophyllum sp.) can dominate shallow areas with high light exposure (Steneck 1986; Littler and Littler 2013; Dean et al. 2015), higher light intensity can also reduce the growth of some CCA via photoinhibition (Burdett et al. 2014). The higher light intensity on the horizontal substrates combined with the inhibitory effects of increased sedimentation may have made horizontal substrates more conducive for the growth of non-crustose algae such as filamentous algae and contributed to the differences in algal communities we observed (Cheroske et al. 2000; Trapon et al. 2013a, b).

The structural complexity of reefs is often positively related to coral cover (Alvares-Filip et al. 2009; Graham and Nash 2013), but fewer studies have looked at how smallscale $\left(<500 \mathrm{~cm}^{2}\right)$ habitat characteristics (reef complexity or substrate orientation) could influence important reef processes such as coral recruitment and species competition (Brock 1979; Vermeij 2006; Doropoulos et al. 2016; Mallela 2018). For instance, complexity of microtopographic refuges can promote coral recruitment by increasing turbulent flow and facilitating the arrival of coral larvae to the substrate (Hata et al. 2017) and by providing microrefuges $(<1000 \mu \mathrm{m})$ where coral larvae prefer to settle (Whalan et al. 2015). Microtopography could also mediate the grazing pressure of herbivores, especially in upward-facing surfaces, and thus their impact over benthic communities promoting local benthic diversity and increasing coral recruitment (Edmunds et al. 2014; Brandl and Bellwood. 2016). Davies et al. (2013) observed that despite high species-specific variation, corals recruited twice as much on vertical substrates compared to horizontal substrates and that corals also displayed lower mortality on vertical substrates.

Thus, the differences in algal communities between horizontal and vertical substrates that we saw could have a significant impact on the recruitment of corals (Trapon et al. 2013a, b). The abundant sediment and macroalgae on horizontal substrates would likely represent poor habitats for coral recruitment (Birrell et al. 2005). In contrast, some species of crustose coralline algae, which were abundant on vertical substrates regardless of herbivory, are strong facilitators of coral recruitment (Littler and Littler 2013; RitsonWilliams et al. 2016). In fact, the few coral recruits that we found during our experiment were only on vertical substrates with abundant crustose algae (photos in Supplementary section II). Our observations suggest that the ongoing reduction of structural complexity in the Caribbean might negatively impact coral recruitment via alterations to the benthic communities and the decline in important microhabitats that facilitate recruitment.

Most of the work investigating the impact of structural complexity on coral reef dynamics has focused on its influence on fish community composition, and the behavior and recruitment of mobile species, particularly fishes (Holbrook et al. 2000; Verges et al. 2011; Catano et al. 2015, 2016). Our data demonstrate that the flattening of reefs at a small scale can significantly influence how herbivores control macroalgal communities. Therefore, the gradual decline in structural complexity on coral reefs (Alvares-Filip et al. 2011) may significantly impact how herbivory impacts benthic community dynamics, which could contribute to important negative feedbacks detracting from the resilience of coral reefs. These differences in how herbivory impacts reef areas of different substrate orientations will be important to incorporate into future modeling efforts aimed at understanding how the loss of complexity impacts reef resilience (e.g., Blackwood et al. 2012; Bozec et al. 2015).

Acknowledgements We appreciate the valuable comments and suggestions provided by several anonymous reviewers as well as Alastair Harborne and Andy Shantz that helped to improve the manuscript. Additionally, we want to thank Mark Ladd and Andy Shantz for their help in the field setting up the experiment. We also want to thank members of the FIU marine macroalgae research lab and the Burkepile Lab at UCSB that collaborated with field data collection, in particular, Amanda Brannon and Alexandra Simmons. This is contribution \#105 from the Center for Coastal Oceans Research in the Institute of Water and Environment at Florida International University.

Funding This work was facilitated by Grant OCE 1130786 from the National Science Foundation to D.E. Burkepile. The funders had no role in study design, data collection, and analysis, decision to publish, or preparation of the manuscript.

\section{Compliance with ethical standards}

Ethical approval The authors declare that all applicable international, national and/or institutional guidelines for sampling, care and experimental use of organisms for the study have been followed and all necessary approvals have been obtained.

Conflict of interest The authors declare that they have no conflict of interest.

Open Access This article is distributed under the terms of the Creative Commons Attribution 4.0 International License (http://creativeco mmons.org/licenses/by/4.0/), which permits unrestricted use, distribution, and reproduction in any medium, provided you give appropriate credit to the original author(s) and the source, provide a link to the Creative Commons license, and indicate if changes were made. 


\section{References}

Adam TC, Burkepile DE, Ruttenberg BI, Paddack MJ (2015a) Herbivory and the resilience of Caribbean coral reefs: knowledge gaps and implications for management. Mar Ecol Prog Ser 520:1-20

Adam TC, Kelley M, Ruttenberg BI, Burkepile DE (2015b) Resource partitioning along multiple niche axes drives functional diversity in parrotfishes on Caribbean coral reefs. Oecologia 179:1173-1185

Alvares-Filip L, Dulvy NK, Gill JA, Cote IM, Watkinson AR (2009) Flattening of Caribbean coral reefs: region-wide declines in architectural complexity. Proc R Soc B 276:3019-3025

Alvares-Filip L, Gill JA, Dulvy NK, Perry AL, Watkinson AR, Cote IM (2011) Drivers of region-wide declines in architectural complexity on Caribbean reefs. Coral Reefs 30:1051-1060

Arnold SN, Steneck RS (2010) Settling into an increasingly hostile world: the rapidly closing "recruitment window" for corals. PLoS One 6:e28681

Birrell CL, McCook LJ, Willis BT (2005) Effects of algal turfs and sediment on coral settlement. Mar Pollut Bull 51:408-414

Blackwood JC, Hasting A, Mumby PJ (2012) The effect of fishing on hysteresis in Caribbean coral reefs. Theor Ecol 5:105-114

Bozec Y-M, Yakob L, Bejarano S, Mumby PJ (2013) Reciprocal facilitation and non-linearity maintain habitat engineering on coral reefs. Oikos 122:428-440

Bozec Y-M, Alvarez-Filip L, Mumby PJ (2015) The dynamics of architectural complexity on coral reefs under climate change. Glob Change Biol 21:223-235

Brandl SJ, Bellwood DR (2016) Microtopography refuges shape consumer-producer dynamics by mediating consumer functional diversity. Oecologia 182:203-217

Brock RE (1979) An experimental study on the effects of grazing by parrotfishes and role of refuges in benthic community structure. Mar Biol 51:381-388

Burdett HL, Keddie V, MacArthur N, McDowall L, Spielvogel E, Hatton AD, Kamenos NA (2014) Dynamic photoinhibition exhibited by red coralline algae in the Red Sea. BMC Plant Biol 139:1-10

Burkepile DE, Hay ME (2007) Predator release of the gastropod Cyphoma gibbosum increases predation on gorgonian corals. Oecologia 154:167-173

Burkepile DE, Allgeir JE, Shantz AA, Pritchard CE, Lemoine NP, Bhatti LH, Layman CA (2013) Nutrient supply from fishes facilitates macroalgae and suppresses corals in a Caribbean coral reef ecosystem. Sci Rep 3:e1493

Carpenter RC (1985) Relationships between primary production and irradiance in coral reef algal communities. Limnol Oceanogr 30:784-793

Carpenter RC (1986) Partitioning herbivory and its effects on coral reef algal communities. Ecol Monogr 56:345-364

Catano LB, Gunn BK, Kelley MC, Burkepile DE (2015) Predation risk, resource quality, and reef structural complexity shape territoriality in a coral reef herbivore. PLoS One 10:e0118764

Catano LB, Rojas MC, Malossi RJ, Peters JR, Heithaus MR, Fourqrean JW, Burkepile DE (2016) Reefscapes of fear: predation risk and reef heterogeneity interact to shape herbivore foraging behavior. J Anim Ecol 85:146-156

Cheroske AG, Williams SL, Carpenter RC (2000) Effects of physical and biological disturbances on algal turfs in Kaneohe Bay, Hawaii. J Exp Mar Biol Ecol 248:1-34

Chiappone M, Rutten LM, Swanson DW, Miller SL (2008) Population status of the urchin Diadema antillarum in the Florida Keys 25 years after the Caribbean mass mortality. In: Proceedings of the 11th international coral reef symposium, NCRI Nova Southeastern University, Dania Beach, USA, pp 712-716
Clausing RJ, Annunziata C, Baker G, Lee C, Bittick SJ, Fong P (2014) Effects of sediment depth on algal turf height are mediated by interactions with fish herbivory on a fringing reef. Mar Ecol Prog Ser 517:121-129

Connell SD, Foster MS, Airoldi L (2014) What are algal turfs? Towards a better description of turfs. Mar EcolProg Ser 495:299-307

Davies SW, Matz MV, Vize PD (2013) Ecological complexity of coral reef recruitment processes: effects of invertebrate herbivores on coral recruitment and growth depends upon substratum properties and coral species. PLoS One 8:e72830

Dean AJ, Steneck RS, Tager D, Pandolfi JM (2015) Distribution, abundance and diversity of crustose coralline algae on the Great Barrier Reef. Coral Reefs 34:581-594

Diaz-Pulido G, McCook LJ (2002) The fate of bleached corals: pattern and dynamics of algal recruitment. Mar Ecol Prog Ser 232:115-128

Doropoulos C, Roff G, Bozec YM, Zupan M, Werminghausen J, Mumby PJ (2016) Characterizing the ecological trade-off throughout the early ontogeny of coral recruitment. Ecol Monogr 86:20-44

Duran A, Collado-Vides L, Burkepile DE (2016) Seasonal regulation of herbivory and nutrient effects on macroalgal recruitment and succession in a Florida coral reef. PeerJ 4:e2643

Edmunds PJ, Nozawa Y, Villanueva RD (2014) Refuges modulate coral recruitment in the Caribbean and the Pacific. J Exp Mar Biol Ecol 454:78-84

Fabricius K, De'ath G (2001) Environmental factors associated with the spatial distribution of crustose coralline algae on the Great Barrier Reef. Coral Reefs 19:303-309

Fabricius K, De'ath G, Noonan S, Uthicke S (2014) Ecological effects of ocean acidification and habitat complexity of reef-associated macroinvertebrate communities. Proc R Soc B 281:20132479

Ferrari R, Gonzalez-Rivero M, Ortiz JC, Mumby PJ (2012) Interaction of herbivory and seasonality on the dynamics of Caribbean macroalgae. Coral Reefs 31:683-692

Goatley CHR, Bellwood DR (2013) Ecological consequences of sediment on high-energy coral reefs. PLoS One 8:e77737

Gordon SE, Goatley CHR, Bellwood DR (2016) Low-quality sediments deter grazing by the parrotfish Scarus rivulatus on inner-self reefs. Coral Reefs 35:285-291

Graham NAJ (2014) Habitat complexity: coral structural loss leads to fisheries declines. Curr Biol 24:359-361

Graham NAJ, Nash KL (2013) The influence of structural complexity in coral reef ecosystems. Coral Reefs 32:315-326

Hata T, Madin JS, Cumbo VR, Denny M, Figueiredo J, Harii S, Thomas CJ, Baird AH (2017) Coral larva are poor swimmers and require fine-scale reef structure to settle. Sci Rep 7:2249

Holbrook SJ, Graham EF, Schmitt RJ (2000) Spatial patterns in abundance of a damselfish reflect availability of suitable habitat. Oecologia 122:109-120

Jackson JBC, Donovan MK, Cramer KL, Lam VV (2014) Status and trends of Caribbean coral reefs: 1970-2012. Global Coral Reef Monitoring Network, IUCN, Gland

Lessios HA (1988) Mass mortality of Diadema antillarum in the Caribbean: what have we learned? Ann Rev Ecol Syst 19:371-393

Lewis SM, Wainwright PC (1985) Herbivore abundance and grazing intensity on a Caribbean coral reef. J Exp Biol Ecol 87:215-228

Littler MM, Littler DS (2013) The nature of crustose coralline algae and their interactions on reefs. Smithson Contrib Mar Sci 39:199-212

Luckhurst BE, Luckhurst K (1978) Analysis of the influence of substrate variables on coral reef fish communities. Mar Biol 49:317-323

Mallela J (2018) The influence of micro-topography and external bioerosion on coral-reef-building organisms: recruitment, community 
composition and carbonate production over time. Coral Reefs 37:227-237

Mapstone BD, Andrew NL, Chancerell Y, Salvat B (2007) Mediating effects of sea urchins on interactions among corals, algae and herbivorous fish in the Moore lagoon, French Polynesia. Mar Ecol Prog Ser 332:143-153

Miller MW, Hay ME, Miller SL, Malone D, Sotka EE, Szmant AM (1999) Effects of nutrients versus herbivores on reef algae: a new method for manipulating nutrient on coral reefs. Limnol Oceanogr 44:1847-1861

Ogden JC, Lobel PS (1978) The role of herbivorous fishes and urchins in coral reef communities. Env Biol Fish 3:49-63

Oksanen J, Blanchet FG, Friendly M, Kindt R, Legendre P, McGlinn D, Minchin PR, O'hara RB, Simpson GL, Solymos P et al (2017) Community ecology package. R package version 2.3-2. http:// CRAN.R-project.org/package $=$ vegan

Perry CT, Murphy GN, Kench PS, Edinger EN, Smithers SG, Steneck RS, Mumby PJ (2014) Changing dynamics of Caribbean reef carbonate budget: emergence of reef bioeroders as critical controls on present and future reef growth potential. Proc R Soc B 281:20142018

Ritson-Williams R, Arnold SN, Paul VJ (2016) Patterns of larvae settlement preferences and post-settlement survival for seven Caribbean corals. Mar Ecol Prog Ser 548:127-138

Roff G, Zhao J-X, Mumby PJ (2015) Decadal-scale rates of reef erosion following El Nino-related mass coral mortality. Glob Change Biol 21:4415-4424

Rogers A, Blanchard JL, Mumby PJ (2014) Vulnerability of coral reef fisheries to a loss of structural complexity. Curr Biol 24:1000-1005

Smith JE, Smith CM, Hunter CL (2001) An experimental analysis of the effects of herbivory and nutrient enrichment on benthic community dynamics on a Hawaiian reef. Coral Reefs 19:332-342

Smith JE, Hunter CL, Smith CM (2010) The effects of top-down versus bottom-up control on benthic coral reef community structure. Oecologia 163:497-507

Soren H (2016) Grouping statistics, LS means, linear contrasts, utilities. R package version 3.2.0. http://CRAN.R-project.org/packa ge $=$ doBy

Steneck RS (1983) Quantifying herbivory on coral reefs: just scratching the surface and still biting off more than we can chew. In: Reaka L (ed) The ecology of deep and shallow coral reefs. Symposia series for undersea research, vol 1. National Oceanic and Atmospheric Administration, Rockville, Maryland, USA, pp 103-111

Steneck RS (1986) The ecology of coralline algal crusts: convergent patterns and adaptive strategies. Ann Rev Ecol Syst 17:273-303
Steneck RS (1997) Crustose corallines, other algal functional groups, herbivores and sediments: complex interactions along reef productivity gradients. In: proceedings of the 8th international coral reef symposium, Panama City, Panama, pp 675-700

Steneck RS, Dethier MN (1994) A functional group approach to the structure of algal-dominated communities. Oikos 69:476-498

Strader ME, Davies SW, Matz MV (2015) Differential responses of coral larvae to the colour of ambient light guide them to suitable settlement microhabitat. R Soc Open Sci 2:150358

R Core Team (2016) R: a language and environment for statistical computing. R Foundation for Statistical Computing, Vienna. http:// www.R-project.org/ (ISBN: 3-900051-07-0)

Tebbett SB, Goatley CHR, Bellwood DR (2017) The effects of algal turf sediments and organic loads on feeding by coral reef surgeonfishes. PLoS One 12:e169479

Trapon ML, Pratchett MS, Hoey AS (2013a) Spatial variation in abundance, size and orientation of juvenile corals related to the biomass of parrotfishes on the Great Barrier Reef, Australia. PLoS One 8:e57788

Trapon ML, Pratchett MS, Hoey AS, Baird AH (2013b) Influence of fish grazing and sedimentation on the early post-settlement survival of the tabular coral Acropora cytherea. Coral Reefs 32:1051-1059

Venables WN, Ripley BD (2002) Modern applied statistics with S, 4th edn. Springer, New York, p 495

Verges AM, Vanderklift A, Doropoulos C, Hyndes GA (2011) Spatial patterns in herbivory on a coral reef are influenced by structural complexity but not algal trait. PLoS One 6:e17115

Vermeij MJA (2006) Early life-history dynamics of Caribbean coral species on artificial substratum: the importance of competition, growth and variation in life-history strategy. Coral Reefs 25:59-71

Whalan S, Wahab MAA, Sprungala S, Poole AJ, de Nys R (2015) Larval settlement: the role of surface topography for sessile coral reef invertebrates. PLoS One 10:e117675

Wickham H (2009) Ggplot2: elegant graphics for data analysis. Springer, New York, p 211

Wilson SK, Graham NAJ, Polunin NVC (2007) Appraisal of visual assessments of habitat complexity and benthic composition on coral reefs. Mar Biol 151:1069-1076

Zaneveld JR, Burkepile DE, Shantz AA, Pritchard CE, McMinds R, Payet JP, Welsh R, Correa AMS, Lemoine NP, Rosales S, Fuchs C, Maynard J, Vega-Thurber R (2016) Overfishing and nutrient pollution interact with temperature to disrupt coral reefs down to microbial scales. Nat. Commun 7:11833 